\title{
How to Quantify the Chaperone-Like (Anti-Aggregation) Activity?
}

\section{Boris I. Kurganov*}

Bach Institute of Biochemistry, Russian Academy of Sciences, Moscow, Russia

Folding of newly synthesized protein chains can be accompanied by the formation of non-native forms prone to aggregation; stress conditions also produce unfolded protein forms which tend to aggregate [1-5]. Investigators aim efforts at the elucidation of the mechanisms of protein aggregation and mechanisms of the protective action of agents possessing chaperone-like (anti-aggregation) activity, namely small heat shock proteins (sHsp) and low-molecular-weight compounds (aminoacids, cyclodextrines, polyamines and so on) [6-8].

The agents possessing chaperone-like (anti-aggregation) activity find application in biotechnology and medicine. To screen agents exhibiting efficient protective action, the quantitative evaluation of the degree of protein aggregation suppression is requisite. Here are discussed the quantitative methods of estimation of the anti-aggregation activity.

\section{Estimation of the initial rate of protein aggregation}

Protein aggregates possess higher light scattering capability in comparison with the non-aggregated protein molecules, and therefore the simple way to register protein aggregation is the measurement of the increment of light scattering intensity $(I)$ or apparent optical absorbance $(A)$. The dependences of $I$ or $A$ on time usually are S-shaped curves, i.e., there is an acceleration of the process in the initial stage. To characterize the initial rate of aggregation, Kurganov [9] proposed to use the quadratic dependence on time $(t)$ :

$$
\mathrm{I}=\mathrm{I}_{\mathrm{o}}+\mathrm{K}_{\text {agg }}\left(\mathrm{t}-\mathrm{t}_{\mathrm{o}}\right)^{2} \text { or } \mathrm{A}=\mathrm{A}_{\mathrm{o}}+\mathrm{K}_{\text {agg }}\left(\mathrm{t}-\mathrm{t}_{\mathrm{o}}\right)^{2},\left(\mathrm{t}>\mathrm{t}_{\mathrm{o}}\right)
$$

Where $I_{0}$ and $A_{0}$ are the initial value of the light scattering intensity and apparent optical absorbance, respectively, at $\mathrm{t}=0$ and $t_{0}$ is the duration of lag period on the kinetic curve ( $t_{0}$ is a point in time at which the light scattering intensity or apparent optical absorbance begins to increase). Parameter $\mathrm{K}_{\mathrm{agg}}$ is a measure of the initial rate of aggregation. The applicability of equation (1) for the description of the initial parts of the kinetic curves of protein aggregation was demonstrated for heat denaturation of glycogen phosphorylase $b(\mathrm{Ph} b)$ [9-12], creatine kinase [13] and glyceraldehyde-3-phosphate dehydrogenase (GAPDH) from rabbit skeletal muscles [14,15] and dithiothreitol-induced aggregation of $\alpha$-lactalbumin [16] and insulin [17]. The measurements of the hydrodynamic radius of protein aggregates using dynamic light scattering allow us to conclude that for the proteins under study the point in time $t=t_{0}$ corresponds to the appearance of start aggregates. Start aggregate contains hundreds of denatured protein molecules. The formation of the start aggregates proceeds on the all-or-none principle. The intermediate states between the non-aggregated protein and start aggregates are not detected in the system [18].

When studying the kinetics of aggregation of polyglutamine peptides [19-21], it was experimentally shown that accumulation of monomers incorporated in the aggregate proceeded according to the time squared law. Theoretical analysis shows that such a law should be valid for nucleation-dependent aggregation $[9,22]$.

The measurement of the $\mathrm{K}_{\mathrm{agg}}$ value at various initial concentrations of the protein $[\mathrm{P}]_{0}$ allows calculating the order of aggregation with respect to the protein $(n)$ :

$$
K_{\text {agg }}=\text { const } \cdot[\mathrm{P}]_{0}^{n}
$$

In the case of thermal aggregation of $\mathrm{Ph} b$ [9] and GAPDH [15] the dependence of parameter $K_{\mathrm{agg}}$ on $[\mathrm{P}]_{0}$ is linear $(n=1)$. This means that the stage of unfolding of a protein molecule proceeds with a substantially lower rate than the following stages of aggregation of the unfolded protein molecules. When unfolding of the protein molecule is a relatively fast process and the stages of aggregation become rate limiting, parameter $n$ exceeds unity. For example, the analysis of the data on thermal aggregation of $\beta_{\mathrm{L}}$-crystallin from bovine lens at $60^{\circ} \mathrm{C}$ (pH 6.8) [23] and thermal aggregation of yeast alcohol dehydrogenase at $56^{\circ} \mathrm{C}$ (pH 7.4) [24] shows that parameter $n$ is close to 2 .

When analyzing the shape of the kinetic curves of aggregation of $\mathrm{Phb}$ denatured by UV radiation [25], we observed that equation (1) is not fulfilled and, to characterize the initial rate of aggregation, we proposed to use the time interval $\left(t_{2 \mathrm{I}}\right)$ over which the initial value of the light scattering intensity is doubled. To calculate the $t_{2 \mathrm{I}}$ value, the initial part of the dependence of the light scattering intensity on time was described by the stretched exponent:

$$
I=I_{0} \exp \left\{(\ln 2)\left(\frac{t}{t_{21}}\right)^{m}\right\}
$$

Where $m$ is a constant. Analysis of the kinetics of aggregation of UV-irradiated $\mathrm{Ph} b$ shows that the initial parts of the kinetic curves can be described by the equation containing simple exponent:

$$
\begin{aligned}
& I=I_{0}\left\{1+K\left[\exp \left(K_{1} t\right)-1\right]\right\}, \\
& I=I_{0}\left\{1+K\left[\exp \left(K_{1} t\right)-1\right]\right\}
\end{aligned}
$$

where $K$ and $K_{1}$ are constants. This equation can be rearranged in a form containing parameter $t_{2 \mathrm{I}}$ :

$$
I=I_{0}\left\{1+K\left[\exp \left(\frac{t}{t_{2 \mathrm{I}}} \ln \left\{\frac{(1+K)}{K}\right\}\right)-1\right]\right\}
$$

The reciprocal value of $t_{2 \mathrm{I}}$, namely $1 / t_{2 \mathrm{I}}$, may be considered as a measure of the initial rate of aggregation. The higher the $1 / t_{2 \mathrm{I}}$ value, the higher is the initial rate of aggregation. It should be noted that the test system based on aggregation of UV-irradiated $\mathrm{Ph} b$, in contrast to the test system based on thermal aggregation of proteins, does not contain the stage of unfolding of the protein molecule. $\mathrm{Ph} b$ denatured by UV irradiation is assembled in primary aggregates with the hydrodynamic radius of $10.4 \mathrm{~nm}$ [25].

*Corresponding author: Boris I. Kurganov, Bach Institute of Biochemistry, Russian Academy of Sciences, Moscow, Russia, Tel: +7(495)952-5641; Fax: +7(495)954-2732; E-mail: kurganov@inbi.ras.ru

Received February 03, 2013; Accepted February 05, 2013; Published February 06, 2013

Citation: Kurganov BI (2013) How to Quantify the Chaperone-Like (AntiAggregation) Activity? Biochem Anal Biochem 2:e136. doi:10.4172/21611009.1000e136

Copyright: $\odot 2013$ Kurganov BI. This is an open-access article distributed under the terms of the Creative Commons Attribution License, which permits unrestricted use, distribution, and reproduction in any medium, provided the original author and source are credited. 
There is another way to characterize the initial rate of aggregation. As noted above, the dependences of the light scattering intensity $(I)$ or apparent optical absorbance $(A)$ on time for aggregation process are usually S-shaped. The analysis of the literature data for the kinetics of protein aggregation shows that at above the inflection point the dependence of $I$ or $A$ on time follows the exponential law [26-30]:

$$
I=I_{0}+\left(I_{\text {lim }}-I_{0}\right)\left\{1-\exp \left[-k_{1}\left(t-t^{*}\right)\right]\right\} \text { or } A=A_{0}+\left(A_{\text {lim }}-A_{0}\right)\left\{1-\exp \left[-k_{1}\left(t-t^{*}\right)\right]\right\}(6)
$$

where $I_{\lim }$ and $A_{\lim }$ are the limiting value of $I$ and $A$, respectively, at $t \rightarrow \infty$ and $t^{*}$ is a length on the $I=I_{0}$ (or $A=A_{0}$ ) horizontal line cut off by the theoretical curve calculated with equation (6). The slope of a tangent to the theoretical curve passing through the point with coordinates $\left\{t=t^{*} ; I=I_{0}\right.$ or $\left.A=A_{0}\right\}$ is equal to the product $k_{\mathrm{I}}\left(I_{\lim }-I_{0}\right)$ or $\mathrm{kI}\left(A_{\lim }-\mathrm{A}_{0}\right)$, which is a measure of the initial rate of aggregation. It should be noted that lag period may be lacking on the kinetic curves of aggregation. This renders using equation (1) and (5) impossible. In such a situation the characterization of the initial rate of aggregation through a product $k_{\mathrm{I}}\left(I_{\lim }-I_{0}\right)$ or $k_{\mathrm{I}}\left(A_{\lim }-A_{0}\right)$ becomes very reasonable, as it was demonstrated by us for thermal aggregation of tobacco mosaic virus coat protein $\left(50 \mathrm{mM}\right.$ phosphate buffer, $\mathrm{pH} 8.0,52^{\circ} \mathrm{C}$; [31]. To determine the order of aggregation with respect to protein, the equation analogous to equation (2) can be used:

$$
k_{\mathrm{I}}\left(I_{\lim }-I_{0}\right)=\mathrm{const} \cdot[\mathrm{P}]_{0}^{n} \text { or } k_{\mathrm{I}}\left(A_{\lim }-A_{0}\right)=\mathrm{const} \cdot[\mathrm{P}]_{0}^{n} .
$$

For thermal aggregation of firefly luciferase [30] and tobacco mosaic virus coat protein [31] parameter $\mathrm{n}$ was found to be close to 2. This means that the rate-limiting stage for the overall process of aggregation is the stage of protein aggregation. The $\mathrm{n}$ value higher than 2 was obtained for heat-induced aggregation of ovalbumin at $80^{\circ} \mathrm{C}$ $(n=2.65$ [32]). It is notable that first-order kinetics $(n=1)$ was observed for thermal aggregation of creatine kinase from rabbit skeletal muscles [33] and aggregation accompanying renaturation of denatured carbonic anhydrase [32]. Thus, the rate-limiting stage for the overall aggregation process is the monomolecular stage (unfolding of the protein molecule in the case of creatine kinase or the initial stage of folding of denatured protein in the case of carbonic anhydrase).

\section{Quantification of anti-aggregation activity of protein chaperones}

When analyzing the dependence of the initial rate of aggregation $(v)$ on the concentration of protein chaperone, one should take into account two circumstances. First, the binding of a chaperone to a protein substrate is rather firm, and suppression of aggregation is studied under the conditions when the initial concentrations of a chaperone and protein substrate exceed sufficiently the dissociation constant for the complex chaperone-protein substrate. This means that the dependence of $v$ on [chaperone] is a titration curve which allows determining the stoichiometry of chaperone-protein substrate complex. Second, in accordance with equation (2) or (7) the protein concentration $[\mathrm{P}]_{0}$ is proportional to $v^{1 / n}$. This means that the proportional decrease in the concentration of the protein substrate (for example, as a result of the complexation with a chaperone) should result in the proportional decrease in the $v^{1 / n}$ value. Thus, to determine the stoichiometry of the chaperone-protein substrate complex, one should construct the $v^{1 / n}$ versus [chaperone] plot. Besides, the dependence of $v$ on [chaperone] may be nonlinear because of the formation of the chaperone-protein substrate complexes with different stoichiometry.

The dependence of $v$ on [chaperone] consisting of two linear parts was observed for suppression of UV-irradiated $\mathrm{Ph} b$ by $\alpha$-crystallin
[25]. The dependence of $v^{1 / n}$ on [sHsp] of such a type is schematically represented in figure 1A. One can assume that the complicated shape of the $v^{1 / n}$ versus [sHsp] plot is due to the dynamic structure of $\alpha$-crystallin and the initial part of the dependence of $v^{1 / n}$ on [sHsp] corresponds to the complexes of the dissociated forms of $\alpha$-crystallin with the protein substrate. The second linear part corresponds to the formation of the $\alpha$-crystallin-protein substrate complexes where the adsorption capacity of $\alpha$-crystallin in respect to the protein substrate becomes decreased. The length cut off on the abscissa axis by the second linear part, $[\mathrm{sHsp}]^{*}$, gives the stoichiometry of the chaperone-protein substrate complex of the second type. The abscissa of the point of intersection for two linear parts gives the stoichiometry of the chaperone-protein substrate complex of the first type. It is significant that the titration curves obtained at various concentrations of the protein substrate should retain the same form in the coordinates $\left\{\left(\mathrm{v} / v_{0}\right)^{1 / \mathrm{n}}\right.$; [sHsp $] /$ [protein substrate] $\}$ where $v_{0}$ is the initial rate of aggregation in the absence of the chaperone. This methodology should be proved by concrete examples.

In works $[32,34,35]$ the $k_{\mathrm{r}} A_{\lim }$ product was used for the quantitative characterization of the chaperone-like activity of whole casein and $\beta$ casein. It is of interest that the $k_{\mathrm{I}} A_{\lim }$ value versus [whole casein] plot for suppression of aggregation accompanying renaturation of denatured carbonic anhydrase by whole casein looks like a curve consisting of two linear parts [32].

Experimental data on suppression of thermal aggregation of the catalytic subunit of protein kinase CK2 $(\mathrm{CK} 2 \alpha)$ at $40^{\circ} \mathrm{C}$ by C-terminal domain of glucose-regulated protein (grp94-CT) obtained by Roher et al. [36] were analyzed by Kurganov [27]. To calculate the initial rate of aggregation, the $k_{\mathrm{I}} I_{\lim }$ product was calculated. The linear character of the dependence of the $k_{\mathrm{r}} A_{\lim }$ value on the molar ratio [grp94-CT]/[CK2 $\alpha$ ] was demonstrated. The following stoichiometry of the grp94-CT-CK2 $\alpha$ complex was calculated from the length cut off on the abscissa axis by the straight line: 4 molecules of grp94-CT per 1 molecule of CK2 $\alpha$.

\section{Quantification of anti-aggregation activity of chemical chaperones}

Protective effect of chemical chaperones is revealed as a diminishing of the initial rate of aggregation in the presence chemical chaperone (Figure 1B). When studying the protective action of chemical chaperones (2-hydroxylpropyl- $\beta$-cyclodextrin [15] or proline [25]), we showed that the dependence of the initial rate of aggregation $v$ expressed by parameter $K_{\mathrm{agg}}$ or $1 / t_{2 \mathrm{I}}$ on the concentration of chemical chaperone (L) followed the Hill equation [37]:

$$
v=\frac{v_{0}}{1+\left([\mathrm{L}] /[\mathrm{L}]_{0.5}\right)^{h}},
$$

Where $v_{0}$ is the initial rate of aggregation in the absence of a chaperone, $[\mathrm{L}]_{0.5}$ is the concentration of semisaturation, i.e., the concentration of the chaperone at which $v / v_{0}=0.5$, and $h$ is the Hill coefficient. The value of $h$ was found to be 1.8 for 2-hydroxylpropyl$\beta$-cyclodextrin and 1.6 for proline. The values of $h$ exceeding unity are indicative of the existence of positive cooperative interactions between chaperone-binding sites in the protein substrate molecule [37]. Parameter $[\mathrm{L}]_{0.5}$ may be considered as a measure of the affinity of the chaperone to the protein substrate. The lower the $[\mathrm{L}]_{0.5}$ value, the higher is affinity of the chaperone to the protein substrate. It is significant that the shape of the dependence of the initial rate of aggregation on the chaperone concentration remains unchangeable at variation of the protein substrate concentration as was shown, for example, for suppression of protein aggregation by proline [25]. 
Citation: Kurganov BI (2013) How to Quantify the Chaperone-Like (Anti-Aggregation) Activity? Biochem Anal Biochem 2:e136. doi:10.4172/21611009.1000e136

Page 3 of 2
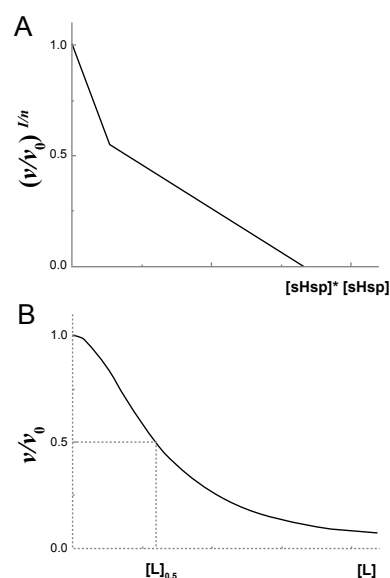

Figure 1: The schematic representation of suppression of protein aggregation by a protein chaperone, sHsp, (A) and a chemical chaperone (B). The dependences of the relative initial rate of aggregation $v / v_{0}$ on the chaperone concentration $\left(v_{0}\right.$ and $v$ are the initial rate of aggregation in the absence and presence of chaperone, respectively); $n$ is a power exponent in equation (2) or (7).

It should be noted that in both cases the UV-irradiated protein (GAPDH [15] or Phb [25]) was used as a protein substrate. It has been just such protein substrates which allowed us to register the effect of chemical chaperones directly on the stage of aggregation of denatured protein molecules. In other test-systems, for example, in the testsystems based on heat-induced aggregation of proteins, the general effect of chemical chaperone involves the action of chaperone on the aggregation stage and the action of chaperone on the stages preceding the aggregation stage $[10,38-40]$.

\section{Combined action of chaperones}

The protective activity of sHsp can be modulated by the chemical chaperones. For example, it was demonstrated that arginine enhanced the chaperone-like activity of $\alpha$-crystallin [40-42]. Since each of the chaperones (sHsp or chemical chaperone) affects protein aggregation, strict quantitative methods should be used to characterize the combined action of chaperones. Parameter $j$ proposed by us for analysis of combined action of inhibitors [43] may be useful for this purpose:

$$
j=\frac{i_{1,2}}{1-\left(1-i_{1}\right)\left(1-i_{2}\right)} \text {. }
$$

In this equation $i$ is a degree of inhibition: $i 1=1-v_{1} / v_{0}$ for inhibitor $1, i_{2}=1-v_{2} / v_{0}$ for inhibitor 2 and $i_{1,2}=1-v_{1,2} / v_{0}$ for the inhibitor $1 /$ inhibitor 2 mixture ( $v 0$ is the initial rate of aggregation in the absence of inhibitors, $v_{1}, v_{2}$ and $v_{1,2}$ are the values of the initial rate of aggregation in the presence of inhibitor 1 , inhibitor 2 and inhibitor $1+$ inhibitor 2 , respectively). When the action of one inhibitor is not dependent on the presence of the other, parameter $j$ is equal to unity. The case $j>1$ corresponds to synergism and the case $j<1$ corresponds to antagonism in the combined action of two inhibitors.

We used parameter $j$ for analysis of combined action of $\alpha$-crystallin and proline on aggregation of UV-irradiated $\mathrm{Ph} b$ [25]. To characterize the initial rate of aggregation, parameter $1 / t_{1 / 2}$ was calculated. When concentration of proline was equal to $0.15 \mathrm{M}$, a slight antagonism was observed between $\alpha$-crystallin and proline (the values of parameter $j$ fall in the interval 0.81-0.91). However, at higher proline concentration $(0.5 \mathrm{M})$ each inhibitor ( $\alpha$-crystallin or proline) acts independently of one another.
Parameter $j$ may be used also for analysis of combined action of protein chaperones. For example, Yousefi and Jalili [44] studied the combined action of $\alpha$-crystallin and $\beta$-casein on dithiothreitol-induced aggregation of bovine pancreatic insulin. The $k_{\mathrm{I}} A_{\lim }$ product was used for characterization of the initial rate of aggregation. The analysis of the data presented in this work shows that parameter $j$ is close to unity. Thus, two chaperones act independently of each other.

This study was funded by the Russian Foundation for Basic Research (grant 11-04-00932-a) and the Program "Molecular and Cell Biology" of the Presidium of the Russian Academy of Sciences.

\section{References}

1. Hartl FU, Hayer-Hartl M (2002) Molecular chaperones in the cytosol: from nascent chain to folded protein. Science 295: 1852-1858.

2. Markossian KA, Kurganov $\mathrm{BI}$ (2004) Protein folding, misfolding, and aggregation. Formation of inclusion bodies and aggresomes. Biochemistry (Mosc) 69: 971-984.

3. Ellis RJ (2011) Protein aggregation: Opposing effects of chaperones and crowding. In: Wyttenbach A, O'Connor V (Eds) Folding for the Synapse. Springer, New York, 9-34

4. Invernizzi G, Papaleo E, Sabate R, Ventura S (2012) Protein aggregation: mechanisms and functional consequences. Int J Biochem Cell Biol 44: 1541 1554.

5. Kurganov $\mathrm{BI}$ (2012) Fundamental aspects of conformational liability of proteins. Biochem Anal Biochem 1: e107.

6. Sun Y, MacRae TH (2005) Small heat shock proteins: molecular structure and chaperone function. Cell Mol Life Sci 62: 2460-2476.

7. Hilton GR, Lioe H, Stengel F, Baldwin AJ, Benesch JL (2013) Small heat-shock proteins: paramedics of the cell. Top Curr Chem 328: 69-98.

8. Hamada H, Arakawa T, Shiraki K (2009) Effect of additives on protein aggregation. Curr Pharm Biotechnol 10: 400-407.

9. Kurganov $\mathrm{BI}$ (1998) Kinetics of heat aggregation of proteins. Biochemistry (Mosc) 63: 364-366

10. Eronina TB, Chebotareva NA, Bazhina SG, Makeeva VF, Kleymenov SY, et al. (2009) Effect of proline on thermal inactivation, denaturation and aggregation of glycogen phosphorylase $b$ from rabbit skeletal muscle. Biophys Chem 141 $66-74$

11. Eronina TB, Chebotareva NA, Kleymenov SY, Roman SG, Makeeva VF, et al. (2010) Effect of 2-hydroxypropyl- $\beta$-cyclodextrin on thermal stability and aggregation of glycogen phosphorylase $b$ from rabbit skeletal muscle. Biopolymers 93: 986-993.

12. Eronina TB, Chebotareva NA, Bazhina SG, Kleymenov SY, Naletova IN, et al. (2010) Effect of GroEL on thermal aggregation of glycogen phosphorylase b from rabbit skeletal muscle. Macromol Biosci 10: 768-774.

13. Maloletkina OI, Markossian KA, Belousova LV, Kleimenov SY, Orlov VN, et al. (2010) Thermal stability and aggregation of creatine kinase from rabbit skeletal muscle. Effect of 2-hydroxypropyl-beta-cyclodextrin. Biophys Chem 148: 121130.

14. Maloletkina OI, Markossian KA, Asryants RA, Semenyuk PI, Makeeva VF, et al. (2010) Effect of 2-hydroxypropyl-beta-cyclodextrin on thermal inactivation, denaturation and aggregation of glyceraldehyde-3-phosphate dehydrogenase from rabbit skeletal muscle. Int J Biol Macromol 46: 487-492.

15. Maloletkina OI, Markossian KA, Chebotareva NA, Asryants RA, Kleymenov SY, et al. (2012) Kinetics of aggregation of UV-irradiated glyceraldehyde3-phosphate dehydrogenase from rabbit skeletal muscle. Effect of agents possessing chaperone-like activity. Biophys Chem 163-164: 11-20.

16. Bumagina ZM, Gurvits BY, Artemova NV, Muranov KO, Yudin IK, et al. (2010) Mechanism of suppression of dithiothreitol-induced aggregation of bovine alpha-lactalbumin by alpha-crystallin. Biophys Chem 146: 108-117.

17. Bumagina Z, Gurvits B, Artemova N, Muranov K, Kurganov B (2010) Paradoxical acceleration of dithiothreitol-induced aggregation of insulin in the presence of a chaperone. Int J Mol Sci 11: 4556-4579.

18. Golub N, Meremyanin A, Markossian K, Eronina T, Chebotareva N, et al. (2007) 
Citation: Kurganov BI (2013) How to Quantify the Chaperone-Like (Anti-Aggregation) Activity? Biochem Anal Biochem 2:e136. doi:10.4172/21611009.1000e136

Evidence for the formation of start aggregates as an initial stage of protein aggregation. FEBS Lett 581: 4223-4227.

19. Chen S, Ferrone FA, Wetzel R (2002) Huntington's disease age-of-onset linked to polyglutamine aggregation nucleation. Proc Natl Acad Sci U S A 99: 1188411889

20. Bhattacharyya AM, Thakur AK, Wetzel R (2005) polyglutamine aggregation nucleation: thermodynamics of a highly unfavorable protein folding reaction. Proc Natl Acad Sci U S A 102: 15400-15405.

21. Vitalis A, Pappu RV (2011) Assessing the contribution of heterogeneous distributions of oligomers to aggregation mechanisms of polyglutamine peptides. Biophys Chem 159: 14-23.

22. Ferrone $F$ (1999) Analysis of protein aggregation kinetics. Methods Enzymo 309: 256-274.

23. Khanova HA, Markossian KA, Kurganov BI, Samoilov AM, Kleimenov SY et al. (2005) Mechanism of chaperone-like activity. Suppression of thermal aggregation of betaL-crystallin by alpha-crystallin. Biochemistry 44: 1548015487.

24. Markossian KA, Golub NV, Khanova HA, Levitsky DI, Poliansky NB, et al (2008) Mechanism of thermal aggregation of yeast alcohol dehydrogenase I: role of intramolecular chaperone. Biochim Biophys Acta 1784: 1286-1293.

25. Roman SG, Chebotareva NA, Kurganov BI (2012) Concentration dependence of chaperone-like activities of $\alpha$-crystallin, $\alpha \mathrm{B}$-crystallin and proline. Int $\mathrm{J}$ Bio Macromol 50: 1341-1345.

26. Kurganov BI (2002) Estimation of the activity of molecular chaperones in testsystems based on suppression of protein aggregation. Usp Biol Khim 42: 89138.

27. Kurganov BI (2002) Kinetics of protein aggregation. Quantitative estimation of the chaperone-like activity in test-systems based on suppression of protein aggregation. Biochemistry (Mosc) 67: 409-422.

28. Kurganov BI (2002) Principles of quantitative estimation of the chaperone-like activity. Tsinghua Science and Technology 7: 331-339.

29. Kurganov BI (2005) Protein aggregation kinetics. In: Burlakova EB, Varfolomeev SD (Eds) Chemical and Biological Kinetics. New Horizons. Volume 2: Biological Kinetics. Koninklijke Brill NV, Leiden, The Netherlands, 251-279.

30. Wang K, Kurganov BI (2003) Kinetics of heat- and acidification-induced aggregation of firefly luciferase. Biophys Chem 106: 97-109.

31. Kurganov BI, Rafikova ER, Dobrov EN (2002) Kinetics of thermal aggregation of tobacco mosaic virus coat protein. Biochemistry (Mosc) 67: 525-533.

32. Khodarahmi R, Beyrami M, Soori H (2008) Appraisal of casein's inhibitory effects on aggregation accompanying carbonic anhydrase refolding and heatinduced ovalbumin fibrillogenesis. Arch Biochem Biophys 477: 67-76.

33. Fedurkina NV, Belousova LV, Mitskevich LG, Zhou HM, Chang Z, et al. (2006) Change in kinetic regime of protein aggregation with temperature increase. Thermal aggregation of rabbit muscle creatine kinase. Biochemistry (Mosc) 71 325-331.

34. Yousefi R, Shchutskaya YY, Zimny J, Gaudin JC, Moosavi-Movahedi AA, et al. (2009) Chaperone-like activities of different molecular forms of beta-casein. Importance of polarity of $\mathrm{N}$-terminal hydrophilic domain. Biopolymers 91: 623632.

35. Zakharchenko NL, Konnova TA, Gogoleva NE, FaÄ $\neg$ ullin DA, Haertle T, et al. (2012) [Chaperone-like activity of beta-casein and thermal stability of alcohol dehydrogenase]. Bioorg Khim 38: 223-228.

36. Roher N, Miró F, Boldyreff B, Llorens F, Plana M, et al. (2001) The C-terminal domain of human grp94 protects the catalytic subunit of protein kinase CK2 (CK2alpha) against thermal aggregation. Role of disulfide bonds. Eur $J$ Biochem 268: 429-436.

37. Kurganov BI (1982) Allosteric Enzymes. Kinetic Behaviour. John Wiley \& Sons, Chichester, 56-60

38. Maloletkina OI, Markosyan KA, Asriyants RA, Orlov VN, Kurganov BI (2009) Antichaperone activity of cyclodextrin derivatives. Dokl Biochem Biophys 427: 199-201.

39. Maloletkina OI, Markossian KA, Asryants RA, Semenyuk PI, Makeeva VF, et al. (2010) Effect of 2-hydroxypropyl-beta-cyclodextrin on thermal inactivation, denaturation and aggregation of glyceraldehyde-3-phosphate dehydrogenase from rabbit skeletal muscle. Int J Biol Macromol 46: 487-492.

40. Srinivas V, Raman B, Rao KS, Ramakrishna T, Rao ChM (2003) Structura perturbation and enhancement of the chaperone-like activity of alpha-crystallin by arginine hydrochloride. Protein Sci 12: 1262-1270.

41. Srinivas V, Raman B, Rao KS, Ramakrishna T, Rao ChM (2005) Arginine hydrochloride enhances the dynamics of subunit assembly and the chaperonelike activity of alpha-crystallin. Mol Vis 11: 249-255.

42. Ecroyd H, Carver JA (2008) The effect of small molecules in modulating the chaperone activity of alphaB-crystallin against ordered and disordered protein aggregation. FEBS J 275: 935-947.

43. Silonova GV, Livanova NB, Kurganov BI (1969) Allosteric inhibition of phosphorylase b from rabbit skeletal muscles. Mol Biol (Mosc) 3: 768-778.

44. Yousefi R, Jalili S (2011) The synergistic chaperoning operation in a Bi-chaperone system consisting of alpha-crystallin and beta-casein: bovine pancreatic insulin as the target protein. Colloids Surf B Biointerfaces 88: 497-504.
Citation: Kurganov BI (2013) How to Quantify the Chaperone-Like (AntiAggregation) Activity? Biochem Anal Biochem 2:e136. doi:10.4172/21611009.1000e136 